\title{
O ESPAÇO DO MAR E O TEMPO DA PESCA: REFLEXÕES SOBRE PESCA ARTESANAL NA VILA DO CASTELO/BRAGANÇA-PA
}

\author{
THE SPACE OF THE SEA AND THE FISHING TIME: REFLECTIONS ON \\ ARTISANAL FISHING IN THE VILLAGE OF CASTELO/ BRAGANÇA-PA
}

\author{
Luis Junior Costa SARAIVA ${ }^{1}$ \\ Jéssica do Socorro Leite CORRÊA²
}

\begin{abstract}
Resumo: O presente ensaio surge a partir da pesquisa de campo com pescadores artesanais na Vila do Castelo, na cidade de Bragança-PA, no período de junho de 2015 a março de 2016. Nossa intenção foi compreender a relação dos pescadores de camarão na região e o fluxo comercial desse não humano. No decorrer da pesquisa nos defrontamos com outras possibilidades e anseios desses atores sociais e o trabalho foi sendo moldando em seus objetivos conforme nos aproximávamos da realidade da pesca de forma mais ampla, agora não apenas voltada a captura do camarão branco, mas com o anseio de compreender a dinâmica de organização espaço/tempo e também das tensões que envolvem o ambiente da pesca, não apenas em aspectos locais, mas de problemas de cunho nacional, com reflexo direto na vida dos pescadores artesanais. Nessa perspectiva, o presente ensaio enfatizará a dinâmica temporal e espacial dos pescadores que cada vez mais vivenciam os impactos de caráter econômico e politico relacionados a pesca. Assim, nossa aproximação com pescadores artesanais possibilitou momentos de reflexão não apenas sobre a realidade da pesca, mas para questões socioambientais mais amplas no contexto das tensões vivenciadas nas Resex.
\end{abstract}

Palavras-Chave: Pesca artesanal. Tempo. Espaço. Bragança.

\begin{abstract}
This paper arises from the field research with artisanal fishermen in the village of Castelo, located in the town of Bragança-PA, from June 2015 to March 2016. Our intention was to understand the relationship of shrimp fishermen in the region and its trade flow. During the research, we faced other possibilities and wishes of those social actors, and the present work was being molded within its objectives as we approached, in a wider way, the reality of fishing, now not only directed to the catch of white shrimp, but with the desire to understand the dynamics of its space/time organization and also the tensions that surround the fishing environment, not only in local aspects, but in national ones, with a direct impact on the artisanal fishermen lives. Under this perspective, this paper will emphasize the temporal and spatial dynamics of fishermen who increasingly experience economic and political impacts related to fishing. Thus, our approach with artisanal fishermen has allowed moments of reflection, not only about the fishing itself, but about environmental issues in the context of the tensions experienced in the Resex.
\end{abstract}

Keywords: Artisanal fishing. Time. Space. Bragança.

\section{Introdução}

A cidade de Bragança-PA é conhecida pela intensa atividade agrícola e pesqueira, e quando fazemos referência a atividade pesqueira é preciso em um primeiro momento iniciar um diálogo com

\footnotetext{
${ }^{1}$ Doutor em Antropologia. Professor Adjunto FACED/UFPA, Campus de Bragança. Membro do grupo de Pesquisa e Estudos Socioambientais Costeiros (ESAC). Professor da Pós-graduação em Linguagens e Saberes na Amazônia/UFPA. E-mail: luisjsaraiva@yahoo.com.br

${ }^{2}$ Mestranda do Programa de Pós-graduação em Linguagens e Saberes da Amazônia / UFPA. Membro do grupo de Pesquisa e Estudos Socioambientais Costeiros (ESAC). E-mail: etieljessica@gmail.com
} 
os pescadores artesanais e assim compreender de que forma grupos sociais distintos desenvolvem técnicas e habilidades específicas para o desenvolvimento de sua atividade, sempre em conformidade com sua realidade, em relação aos diferentes espaços socioambientais.

O trabalho em questão é resultado da pesquisa realizada com pescadores artesanais na Vila do Castelo na cidade de Bragança-PA, com trabalho de campo realizado entre junho de 2015 a março de 2016. O objetivo inicial foi acompanhar o cotidiano de pescadores no seu espaço de trabalho, identificando sua ampla relação com o espaço ambiental e social da pesca, assim para a realização do trabalho de campo, acompanhamos um grupo de pescadores em atividade de pesca tanto as proximidade da vila, quanto nos ranchos em praias mais afastadas. Os pescadores em destaque na pesquisa são principalmente três, com idades entre 25 anos a 32 anos.

Os ranchos são construções feitas em madeira e geralmente cobertos de palha, servem para abrigar os pescadores enquanto permanecem na praia por períodos que podem oscilar entre 2 a 15 dias. Em sua simplicidade e rusticidade, servem aos objetivos que se destinam, ou seja, abrigar temporariamente pescadores em suas atividades de pesca, como na figura 1 apresentada a seguir.

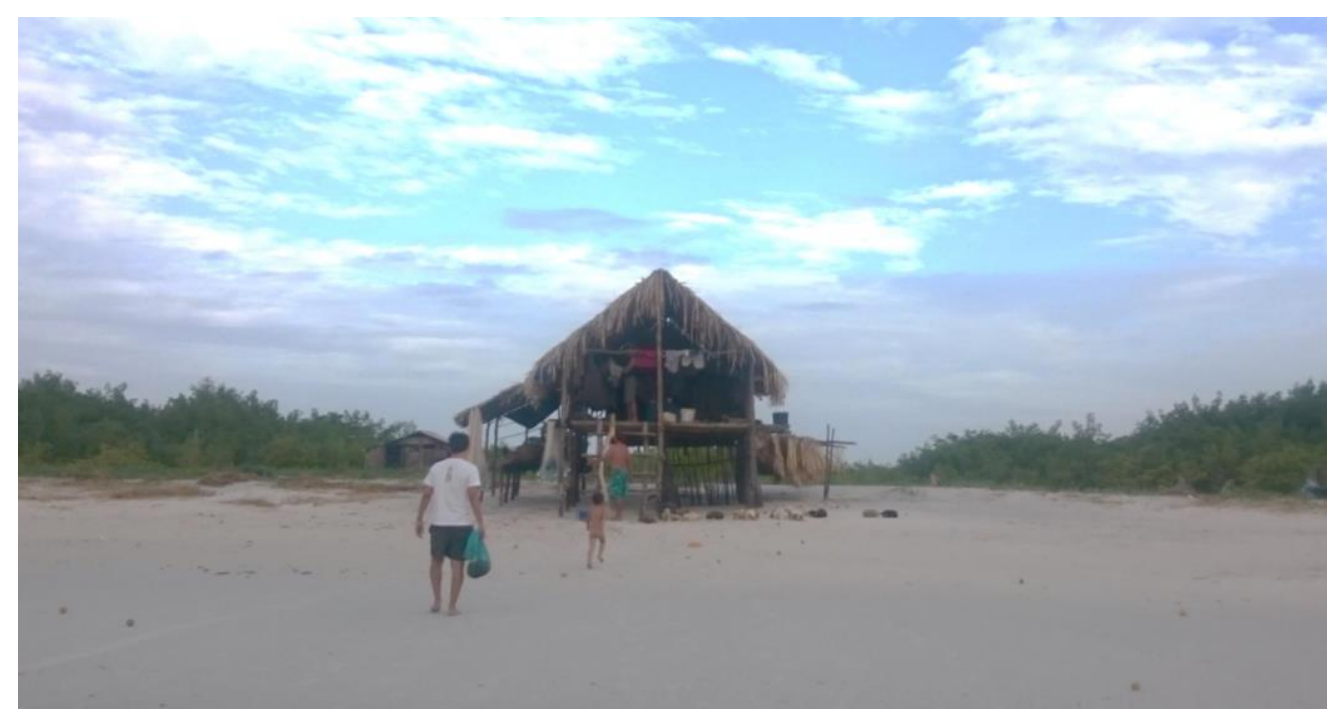

Figura 1- Rancho na praia Lombo do Cachorro / Fonte: Arquivo Pessoal

O rancho é a casa temporária do pescador, nela ele estará protegido da exposição ao sol ou a chuva até o momento propicio (tempo) para a saída ao mar e inicio da pescaria. A viagem até a praia tem duração de aproximadamente duas horas e trinta minutos, ao chegar todos colaboram na organização do almoço, limpeza do espaço, coleta de madeira para fazer o fogo e também captura do pescado para a alimentação daquele momento.

Retornando ao aspecto tempo, quando pensamos nele podemos fazer uma reflexão que inevitavelmente será associada a nossa organização temporal, mas quando pensamos nesse tempo 
especifico para o contexto da pesca somos convidados a uma aproximação do contexto, vivenciar os momentos, sentir cada elemento que o envolve, caso contrário dificultará a compreensão da socialidade entre humanos e não humanos. Nessa perspectiva o trabalho de campo permitiu uma aproximação da atividade da pesca para um entendimento satisfatório da relação dos atores sociais em evidência nesse contexto.

O objetivo inicial do trabalho, que em um primeiro momento correspondia a compreensão dos saberes de pescadores artesanais, foi melhor se estruturando a partir da construção dialógica com os pescadores e à medida que nos aproximávamos das atividades pesqueiras, consolidando a intencionalidade do trabalho com os resultados das pescarias realizadas, que não correspondeu em alguns momentos ao que era esperado pelos pescadores e que em outros o sucesso foi garantido (a pescaria foi satisfatória). Surge então a necessidade de compreender como humanos e não humanos se relacionam e de que forma é construída as justificativas para, em determinados momentos, a falta de peixe, por exemplo, ser justificada pela construção imagética da coloração da água ou da presença/ausência de determinada espécie.

É válido ressaltar que para além de fenômenos ligados a não humanos, as interferências humanas também contribuem em grande escala com a diminuição desse pescado, em outras palavras os discursos dos pescadores nos aproximam de uma memória recorrente a um tempo de grande quantidade de peixes e da facilidade em capturá-los, sendo a produção satisfatória para a venda e também para a alimentação do pescador e sua família. E acrescentavam ainda em seus discursos que eles, nesse período em destaque em suas memórias, o qual é construído imageticamente como um período de grande abundância, em que os pescadores eram parados pela quantidade de peixe capturada. Nesse aspecto o tempo da pescaria era definido pela capacidade de peso suportado pela embarcação de pequeno porte, além da definição temporal ser dada também pela presença ou ausência dos não humanos, o que acontece até os dias atuais.

Nessa perspectiva a pesquisa nos levou a um mergulho mais profundo no oceano da atividade pesqueira, no que tangia a presença ou ausência de investimentos governamentais, as ações politicas, sociais e ambientais que consideramos atingir a dinâmica de vida de pescadores artesanais. A medida que o mergulho nessa realidade ia acontecendo fomos percebendo o conjunto de informações fundamentais para o entendimento das diversas lógica envolvidas na atividade da pesca. No tópico seguinte suscintamente são destacadas algumas tensões existentes no contexto da pesca, tensões essas que tem como força motriz a ideia de desenvolvimento.

\section{O pescador e as tensões da pesca}


As habilidades desenvolvidas pelos pescadores artesanais são as mais diversas que surgem a partir da busca por adequar-se as influências não humanas, e vão desde modificações técnicas às mudanças de tempo, espaço e estilo. Em relação ao tempo, destacamos este enquanto aspecto central da atividade pesqueira, pois de nada adiantaria as mais sofisticadas mudanças técnicas sem o mínimo entendimento do tempo que associado ao espaço e também ao estilo de pescar fazem toda a diferença no resultado da pescaria. Entretanto o sucesso constante das pescarias não depende somente do entendimento dos aspectos já elencados anteriormente (tempo, espaço, técnica e estilo), pois existem problemáticas voltadas às tensões sociais e políticas, que serão apresentadas no decorrer do trabalho. A definição do tempo especifico para cada pescaria está diretamente associada a compreensão de aspectos não humanos, no que tange o comportamento das espécies de pescado, quanto a dinâmica do mar (enchente, vazante, preamar, temperatura, salinidade e outros), além de elementos outros que sinalizam momentos propícios ou não a pescaria.

Considerando todas as movimentações dos pescadores artesanais em melhorar a pescaria, fazendo as adequações necessárias em relação às técnicas, tempo e espaço, mesmo com toda essa dinâmica de constante adaptação, ainda assim algumas questões na prática não correspondem às memórias que surgem nos diálogos, lembranças essas ligadas a um tempo de abundância destacadas constantemente por eles, como relatado, por exemplo, por Zico, pescador artesanal e morador na Vila do Castelo que trabalha na atividade de pesca a vinte anos, que não deixa de destacar em seus relatos as mudanças ocorridas nos últimos anos.

\footnotetext{
Na época em que eu era mais novo e pescava com meu pai, a gente ia rapidinho aqui na frente da vila, ai nessa frente do Castelo mesmo, nessa época era muito peixe, gó, bandeirada, pescada amarela, até mero tinha, tudo quanto era peixe, aqui perto mesmo, tu ia gostar de ver. Teve vez de pegar até 15 seroada de gó. Hoje a gente passa até cinco dias no rancho pra conseguir umas duas ou três seroada.
}

(Pescador Romieu, diário de campo: 01.04.2016)

A falta de peixe destacada no relato de Zico pode ser facilmente comprovada a partir do acompanhamento desses pescadores durante a atividade de pesca, a exemplo, em uma das viagens em que realizamos com os pescadores a uma praia mais distante, na qual passamos três dias acompanhando as pescarias, a quantidade de pescado capturado não chegou a corresponder nem ao que era equivalente a uma seroada. $\mathrm{O}$ pescador utiliza a expressão seroada para se referir tanto a uma medida de peso, quanto a um item (paneiro) utilizado para transportar o pescado, essa é uma denominação regional, atualmente pouco utilizada por pescadores artesanais, a qual corresponde a uma quantidade de peixe equivalente a 15 quilos.

O trabalho do pescador artesanal sofre consequência direta da pesca realizada por embarcações de grande porte, denominada de pesca industrial, existe uma evidente diferença no estilo utilizada por cada prática, a exemplo das próprias embarcações utilizadas por ambos, na região em foco na pesquisa, 
a região bragantina, as embarcações de caráter artesanal são pequenas e suportam uma pequena quantidade de pescado (ver figura 2), essas embarcações em sua maioria são construídas pelos próprios pescadores. Na pesca de arrasto, por exemplo, a embarcação funciona apenas como transporte, pois as redes são lançadas e arrastadas pelos próprios pescadores.

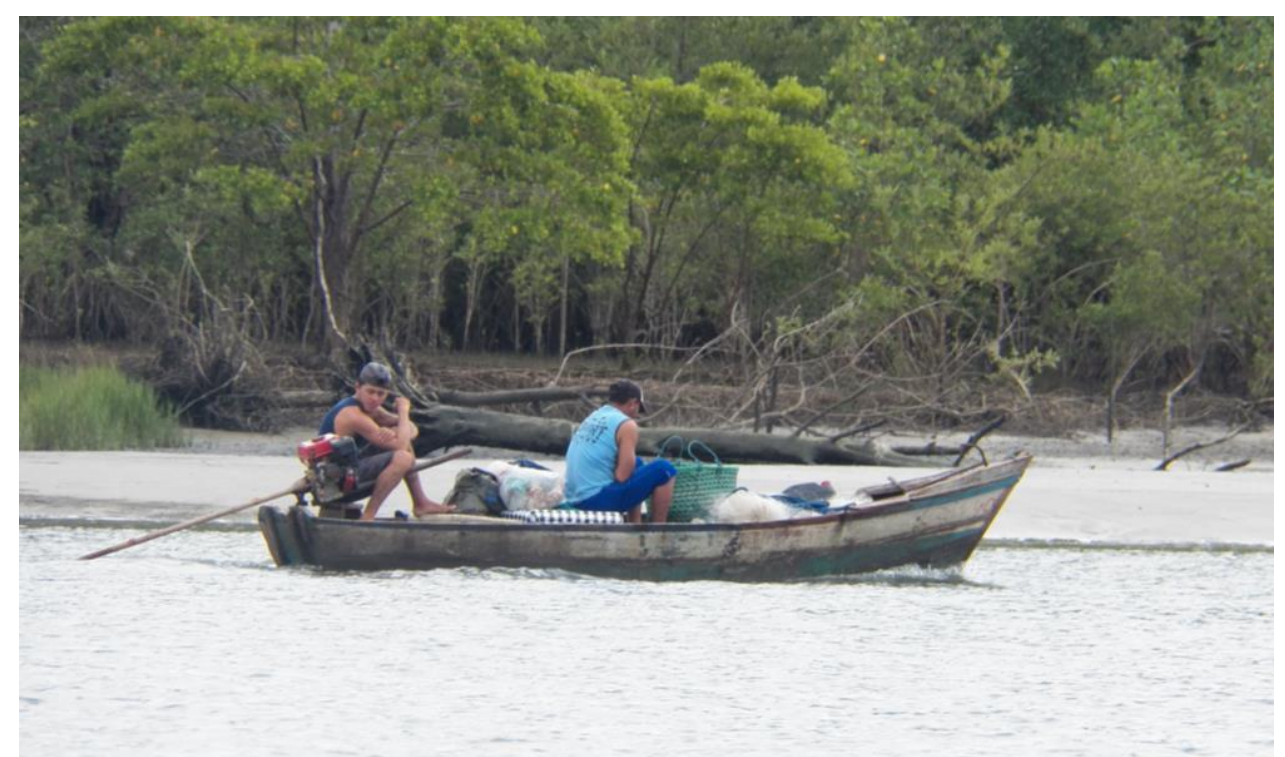

Figura 1- Estilo de embarcação utilizada na região / Fonte: Arquivo Pessoal

Em relação a pesca industrial, as embarcações são equipadas com tecnologias que proporcionam um suporte tanto durante o lançamento das redes quanto durante seu arrasto. Em pesquisa realizada na cidade de Recife-PE por Andrade (2016, p. 25) as embarcações utilizadas na pesca artesanal para o arrasto do camarão utilizam de polpa simples e polpa dupla, para melhor entendimento são destacados abaixo na figura 3 o arrasto realizado por rede de polpa dupla em comparação a figura 4 representando o arrasto realizado por pescadores artesanais na região bragantina. 

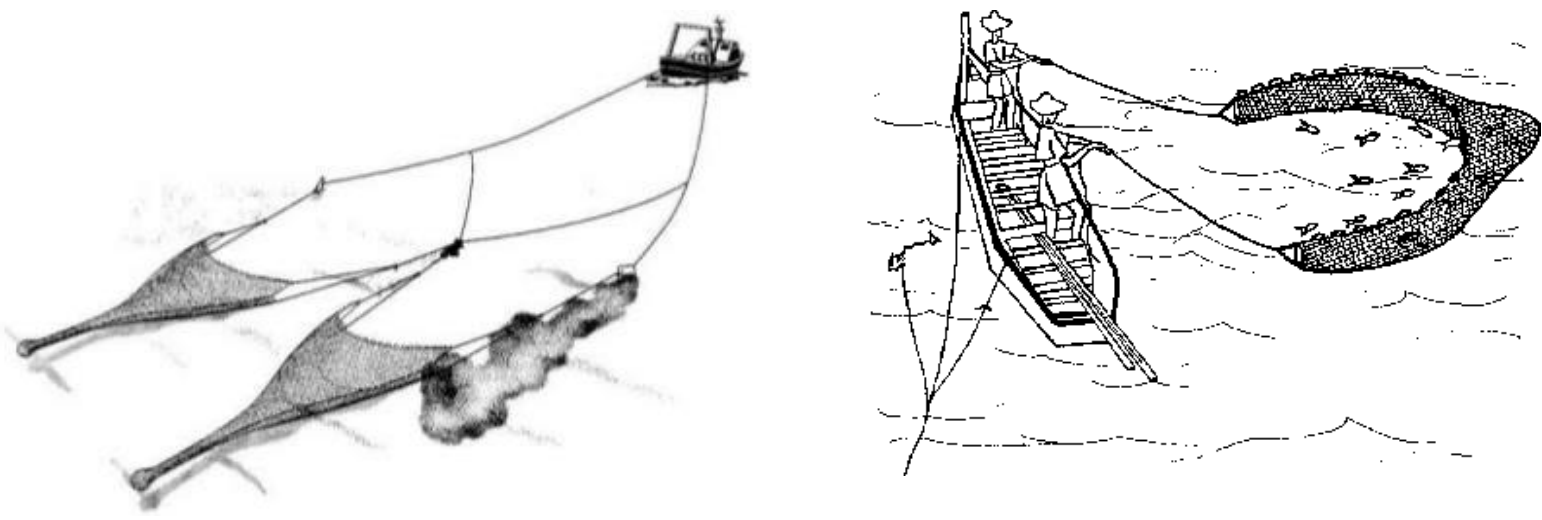

De acordo com Andrade (2016), o estilo de pesca destacado na figura 3, utiliza de embarcações com capacidade de captura de no mínimo 10 t (dez toneladas) em pescarias com duração de 5 a 15 dias, ele pontua ainda que esse estilo de arrasto é o mais predatório, pois ao realizar a pescaria, além da espécie desejada, no caso de sua pesquisa o camarão, a rede captura ainda uma quantidade relativamente grande de fauna acompanhante (diversas espécies de peixe, esponjas do mar, algas e outros), essa fauna acompanhante é identificada como lixo, o autor destaca ainda que para cada 1 quilo de camarão capturado são descartados 9 quilos de fauna acompanhante. (ANDRADE, 2016, p.42).

Nesse aspecto para uma reflexão sobre os estilos de pesca representados nas figuras 3 e 4 é interessante considerar as contribuições de Santos (2003) "quando um determinado ator não tem condições para mobilizar as técnicas consideradas mais avançadas, torna-se, por isso mesmo, um ator de menor importância no período atual" (SANTOS, 2003, p. 35). O autor fala das comunidades tradicionais que acabam ficando a margem do acesso a informações em uma sociedade que cultua o consumo e que hegemoniza os que se adequam as essas novas perspectivas, em outras palavras, aos que podem ter acesso a bens e se adequar aos avanços exigidos pela pesca predatória, adequando-se a demanda de produção cada vez mais intensa que exige embarcações mais bem estruturadas e equipamentos mais avançados. A associação entre a tirania do dinheiro e a tirania da informação conduz, desse modo, a
aceleração dos processos hegemônicos, legitimados pelo pensamento único (...) os
processos não hegemônicos tendem a desaparecer fisicamente, seja a permanecer, mas de
forma subordinada, exceto em algumas áreas da vida social (...). Mas tal situação é sempre
precária, seja porque os resultados localmente obtidos são menores, seja porque os
respectivos agentes são permanentemente ameaçados pela concorrência das atividades
mais poderosas.

(Santos, 2003. p. 35)

Para melhor elucidar as questões relacionadas a pesca artesanal e a pesca industrial, de acordo com Batista et al (2004) em relação as categorias de captura do pescado na região Costeira da Amazônia, ele destaca primeiramente que até a década de 40 as embarcações utilizadas na pesca eram "primitivas" 
e a partir dos anos 60 com o surgimento dos incentivos fiscais e com a liberação da entrada de empresas pesqueiras na região acelerou o desenvolvimento tecnológico da pesca (BATISTA et al, 2004, p. 65)

De acordo com o Ministério da Pesca e Aquicultura (MPA) atualmente a pesca industrial em todo o Brasil conta com a atuação de 1.600 embarcações, tendo 6 principais portos de desembarque, entre eles um na cidade de Belém-PA. De acordo com informações do MPA, desde 2004 são feitos incentivos financeiros para a ampliação da frota pesqueira industrial através do PROFROTA.

Em relação a pesca artesanal na cidade de Braganca, de acordo com Espirito-Santo e Isaac (2012, p. 7), 948 embarcações atuaram nos portos da cidade, a maioria era proveniente do estado do Pará (97\%) distribuídas em 34 portos de origem e as demais de outros estados. Em relação a assistência, destaca que os serviços de assistência técnica para a pesca artesanal no Nordeste Paraense se "constituem num dos pontos mais frágeis da atividade”, ressalta ainda na urgência de preenchimento dessa lacuna, considerando a realidade dos pescadores, como ele acompanhou de perto durante sua pesquisa, "as comunidades que sobrevivem da pesca artesanal estão submetidos e marcados pela pobreza rural".

Para Peixoto (2011, p. 103)

\begin{abstract}
a pesca artesanal em termos de produção pesqueira, geração de empregos, fornecimento de alimentos e divisas, como se trata de uma atividade menos impactante para o meio ambiente, é mais sustentável que a pesca industrial, o que não quer dizer que ambas não possam conviver. Porém, o modelo de desenvolvimento brasileiro, concentrador de renda, voltado para a exportação nas grandes empresas, veio acentuar o abandono da pequena produção, particularmente da pesqueira. Os reflexos desse abandono são sentidos nas esferas regionais e estaduais.
\end{abstract}

(PEIXOTO, 2011, p. 103)

A estrutura econômica que rege o sistema político no país nos arrasta para uma exclusão cada vez mais acentuada de comunidades tradicionais, fazendo com que essas reestruturem seu estilo de vida, buscando se homogeneizar aos demais. Entretanto esse movimento de adequação leva junto toda uma construção cultural que ainda dialoga harmoniosamente com as questões ambientais e também sociais, principalmente em relação a reciprocidade com os humanos e também os não humanos.

Em relação ao aspecto da reciprocidade, percebemos no sentido de apoio mútuo estabelecido entre eles, em momento que envolve problemas de saúde vivenciado por determinado pescador, problemas com as embarcações, falta de equipamentos, em todas essas situações eles se auxiliam. Aos não humanos, percebemos o respeito pelos elementos ambientais, em atitudes, por exemplo, de devolução de espécies pequenas ao mar após a captura.

O trabalho de Andrade (2016) tinha como objetivo para além da análise das dinâmicas da pesca, testar mecanismos que quando acrescentados nas redes durante o arrasto poderia diminuir a captura da fauna acompanhante. Em suas considerações ele destaca que havia uma resistência por parte dos pescadores em utilizar os apetrechos sugeridos devido a diminuição na quantidade de camarão 
capturado. Nessa perspectiva acrescento a fala de um pescador artesanal da cidade de Bragança que também acompanhamos na atividade de pesca, Sr. Antônio tem 73 anos, com mais de 50 anos de profissão, dialoga sobre as dificuldades vivenciadas pelos pescadores artesanais que esbarra em questões políticas.

\begin{abstract}
O IBAMA fica controlando as nossas redes de pesca, mas devia tá de olho nos barcos grandes que pescam ai fora, que tem redes enormes ligadas a bases de ferro que saem arrastando tudo, até o que tá no fundo, pega o pequeno e o grande, pega tudo, e ainda destrói o local que os peixe desovam. Nesses locais em que esses barcos pescam não fica mais nada. O peixe não chega mais na costa, é tudo pescado lá fora, onde só da para pescar com esses barcos grandes, nossos barcos pequeno não vão lá. Se a gente trabalhar só com o malheiro que é permitido fica difícil de pegar muito peixe, ai não da pra vender, só pra comer. Quando era antigamente o tamanho do peixe era diferente, o serra que a gente pescava era maior, a gó também, esse peixe agora é tudo miúdo, não da tempo de crescer, e nem de desovar e tudo uns filhinho de peixe.
\end{abstract}

(Pescador Sr. Antonio, diário de campo: 13.07.2015)

Esse pescador artesanal consegue ter uma ampla visão do cenário atual, dos conflitos que envolvem a pesca, do grau de consequências que sua atividade vem sofrendo ao longo dos anos, no decorrer da conversa ele apresenta mais questões nocivas ao ambiente, como por exemplo, o fato desses barcos ao chegarem ao porto descartarem no rio todo óleo utilizado durante a pescaria, ele ainda alinhava essas informações para as consequências futuras tanto ao ambiente quanto a vida de cada humano.

Em relação aos pescadores mais novos em destaque na pesquisa, eles não conseguem fazer todo o percurso reflexivo que faz o pescador supracitado, mas ambos mergulham em suas memórias para desfrutarem de um tempo de abundância, em que rápido os barcos retornavam do mar cheios de seroadas de peixe. Entretanto, assim como observado por nós e também elucidado pelos pescadores, essas memórias são transversalmente atingidas pelo exato momento da escassez desse pescado, no sentido não somente da falta, mas também da diminuição do tamanho e da quantidade destes. Assim a partir das vivências foi possível observar os esforços dos pescadores em relação a (re) adequação do tempo, do espaço, das técnicas e de toda uma dinâmica completamente comprometida frente a essa realidade.

Nesse sentido é válido ressaltar que a memória não tem um caráter individual, ela está relacionada a um coletivo, que nesse caso é ligado a realidade da pesca, ambos os pescadores vivenciam essa atividade desde a infância. Assim, autores como Bosi (1994) e Braga (2000) reforçam que a memória é um processo elaborado coletivamente que surge na inter-relação entre indivíduo e sociedade, culturalmente sustentada, na qual a memória não é estática e os conteúdos e modos de recordação são determinados por influências sociais, e no caso da presente pesquisa também por influências ambientais.

Para ampliar ainda mais o alcance analítico, Le Goff (1990, p. 411) define que a memória é o espaço onde a história é construída e alicerçada, ela procura trazer o passado para servir o presente e 
o futuro, para que dessa maneira a memória coletiva sirva para a "libertação e não para a servidão dos homens".

\section{O tempo e o espaço da pesca}

Pescaria $^{\mathrm{i}}$

Cesto de peixes no chão.

Cheio de peixes, o mar.

Cheiro de peixe pelo ar.

E peixes no chão.

Chora a espuma pela areia, na maré cheia.

As mãos do mar vêm e vão, as mãos do mar pela areia

a onde os peixes estão.

As mãos do mar vêm e vão, em vão.

Não chegarão aos peixes do chão.

Por isso chora, na areia, a espuma da maré cheia.

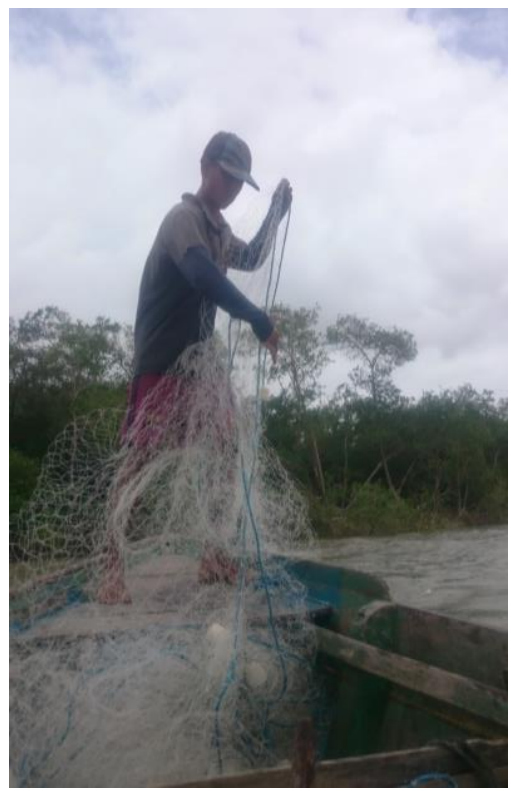

Figura 2 - Pescador organizando a rede para lança-la ao mar/ Fonte: Arquivo Pessoal

Alguns meses antes de receber o convite dos pescadores para acompanha-los na atividade pesqueira ficamos observado os momentos de chegada das pescarias, na ocasião eles realizavam a pesca do camarão, logo que chegavam as crianças principalmente corriam para acompanhar o desembarque e estar próximas do momento de comercialização. Enquanto o comprador do camarão esperava, os pescadores cuidadosamente retiravam o camarão da caixa de isopor e colocavam dentro de um paneiro para escorrer o excesso de água e em seguida faziam a pesagem para depois retornarem o camarão para a caixa com gelo e água. Todo esse processo acontece em um tempo bem peculiar, ainda tínhamos o privilégio de esperar tudo acontecer ouvindo as histórias daquela pescaria, assim nem percebíamos o quanto o tempo cronometrado no relógio se esvaia com tanta rapidez.

Ao sair para a primeira pescaria, foi preciso realizar uma travessia de barco com duração de duas horas e trinta minutos, nessa experiência procuramos ficar atentos a todos os detalhes, chegamos na praia ainda sob a luz do dia, ajudamos a organizar o rancho e ainda brincamos com as crianças antes do início da noite. Quando o sol estava se pondo e o mar estava no fím de sua vazante, saímos em direção ao mar com as redes de pesca, a luz apenas das estrelas e de nossas lanternas, enquanto dois pescadores entram 
na água para arrastar as redes, ficamos a espera na beira da praia. Após 2 horas de atividades e com um número insuficiente de peixes capturados, até para o jantar de quem acompanhava a pescaria, retornamos ao rancho. Nesse momento todas as conversas estavam direcionadas em buscar explicações para o acontecido, e um dos primeiros argumentos apresentados pelos pescadores relacionavam-se a luminosidade da água e sua coloração, em um fenômeno denominado por eles como maré das águas verdes.

Nessa movimentação na busca por explicações acreditamos que os pescadores detêm um conjunto de saberes e habilidades em relação a água, direcionamos então nossa atenção para a água enquanto elemento não humano ${ }^{\mathrm{ii}}$ em relação com os humanos, ela configurasse também como uma entidade que possui características especificas dependendo do seu estado, quando verde tem características peculiares, diferente da água preta. A forma como os pescadores falam da água é a forma como eles falam de um ser humano, como figurado no relato do pescador Romieu, o qual já detém todo um conjunto de experiências no contexto da pesca em relação também aos estilos da água.

\begin{abstract}
A água preta levou tudo, depois ela trás novamente, essa água verde veio ai do norte, veio com o vento do norte. Ele que veio trazendo essa água. A água preta é a água de peixe, ela dá muito peixe, mas a água verde não, quando está assim os peixes que tem enxergam a rede e fogem, por que a água fica acendendo, a gente consegue ver os peixes no fundo brilhando.
\end{abstract}

(Pescador Romieu, diário de campo: 01.02.2016)

Em meio a muitas reclamações presenciamos o desanimo dos pescadores com o contexto atual da pesca e a esperança futura quando a água preta trouxer os peixes que levou. Uma esperança que se prolonga em uma espera que pode ser frustrada caso essa quantidade de peixes que existiam antes, não volte a existir.

A velocidade com que o desenvolvimento humano acontece, assim como o uso predatório de determinados recursos naturais, podem aproximar humanos e não humanos de consequências negativas. A questão é que as comunidades tradicionais são as que sentem essas consequências de maneira mais impactante em suas vidas.

O trabalho dos pescadores não tem horário fixo, o tempo está em dinâmica com as reações da maré e fora do mar o trabalho continua, fazendo o concerto da rede e dos demais apetrechos de pesca. Eles ainda podem ser surpreendidos com momentos como o que apresentamos no inicio do tópico, em que simplesmente não conseguiam capturar uma quantidade suficiente de pescado para cobrir as despesas que realizam durante a atividade (combustível, água, alimentos). Eles acompanham o ritmo do mar, o qual define o momento de inicio e fim da pescaria, obedecendo respectivamente o momento de sua vazante e o inicio de sua enchente. 
A partir do apresentado é válido identificar que a praia em destaque na pesquisa é utilizada por pescadores que moram na reserva extrativista marinha Caeté-Taperaçu (Bragança-PA). E a proposta fundamentadora da reserva consiste, de acordo com o decreto nacional de 20 de maio de 2005, conforme consta no Art. $2^{0}$ "A Reserva Extrativista ora criada tem por objetivo proteger os meios de vida e garantir a utilização e a conservação dos recursos naturais renováveis, tradicionalmente utilizados pela população extrativista na área de sua abrangência".

Na busca por identificação dos direitos dos grupos pesqueiros artesanais, que de acordo com o decreto identificado anteriormente, fica evidente que eles deveriam estar amparados legalmente em relação ao uso sustentável desses recursos no entorno da reserva, que tem uma área de abrangência insuficiente levando em consideração a intensificação da atividade pesqueira industrial, o que faz com que os pescadores artesanais sintam suas consequências cada vez com mais intensidade.

Guattari (2001, P. 12) já apontava, diante do caminho que a humanidade percorria, para um "paradoxo lancinante", no qual estava evidente que de um lado existia o rápido desenvolvimento técnico-cientifico com uma grande potencialidade e do outro a incapacidade das forças sociais, no sentido de domínio e aplicação desses meios para torna-lo operativo. Essas questões tensas nos conduzem a pensar sobre a presente realidade e seus reflexos para o futuro, nos convidando a refletir sobre a importância do trabalho coletivo em prol do bem comum dessas populações tradicionais.

A pesquisa é voltada para pescadores artesanais, mas as questões apresentadas não alcançam apenas a eles, toda a sociedade humana e não humana consegue sentir, mesmo sem perceber, os reflexos de tudo o que foi apresentado, o pescador artesanal ainda será o humano que sentirá essas mudanças com mais intensidade. Caberá agora sensibilizar nossas ações e pensar juntos em possibilidades para o bem comum.

\section{Considerações}

Em aspectos gerais as sociedades tradicionais no país sofreram e ainda sofrem constantes "perturbações" ancoradas no discurso de desenvolvimento, o que resultou em um mar de ocorrências negativas na vida desses atores sociais. Foi a partir das lutas populares, que surgiu em meados dos anos 80 do século XX a política de criação das Reservas Extrativistas, esse marco histórico iniciou no Acre com os seringueiros e resultou na criação da Reserva Extrativista Chico Mendes, esse movimento impulsionou outras sociedades tradicionais em todo país que buscavam um espaço em que pudessem ter seus direitos garantidos legalmente, em relação ao uso sustentável dos recursos naturais. 
No geral percebemos nas falas dos pescadores que suas memórias proporcionam uma viagem pelas lembranças de um tempo bom, em que era possível viver de maneira harmoniosa com o ambiente, em que as águas eram as responsáveis por levar o peixe e traze-los novamente em abundância, alguns até identificam as consequências das grandes embarcações utilizadas na pesca industrial, mas se veem pequenos demais para fazer algo a esse respeito e a solução mais imediata encontrada é tentar se adequar a essa escassez de pescado e relatar essa abundância que hoje só existe na memória.

O trabalho apresentado é o ponto de partida para uma discussão ampla de um modo de vida que está ameaçado. Os tradicionais pescadores artesanais, que nas atuais configurações sociais, estão a mercê da própria sorte, ou da bondade dos não humanos, como a água verde ou a água preta, para mandar o peixe de volta. Como o peixe nem sempre volta, a frustação toma conta do pescador artesanal que hoje precisa trabalhar dobrado para capturar quantidades bem menores de pescado.

A sensação de impotência diante do novo cenário pesqueiro para asses atores sociais não é animador, o que foi possível visualizar na pesquisa ainda em andamento, realizada nos espaços de pesca aqui referidos. Deixando o campo, nos acompanhou as imagens construídas a partir da memória dos pescadores, enquanto ecos de um passado em que riam felizes contando seroadas e mais seroadas de peixe que eram pescados com mais facilidade e com mais rapidez. Ao redor da fogueira na qual comemos o pouco peixe que foi pescado, foi possível ouvir muitas histórias desse tempo, um tempo de abundância que no ritmo de predação atual, fica cada vez mais preso a um passado cada vez mais distante.

\section{Referências:}

ANDRADE, Carlos Eduardo Rangel de. Caracterização da Pesca de arrasto camaroeiro com portas no estado de Pernambuco e medidas mitigadoras de seu impacto ecológico. 2016. 370 f. Tese (Doutorado em Recursos Pesqueiros e Aquicultura)-Universidade Federal Rural de Pernambuco, RecifePE, 2016.

BATISTA, Vandick da Silva. ISAAC, Victoria Judith. VIANA, João Paulo. Exploração e manejo dos recursos pesqueiros da Amazônia In: A Pesca e os recursos pesqueiros na Amazônia. Manaus: Ibama, ProVárzea, 2004.

BOSI, Ecléa. Memória e sociedade: lembranças de velhos. São Paulo: Companhia das Letras, 1994.

BRAGA, Elizabeth dos Santos. A constituição social da memória: uma perspectiva históricocultural. Ijuí: Editora UNIJUI, 2000.

BRASIL. Ministério da Pesca e Aquicultura. Pesca artesanal e industrial. Disponível em: $<$ http://www.mpa.gov.br/pesca/industrial> Acessado em: 25.02.2016. 
Taperuçu.

ESPÍRITO-SANTO, Roberto Vilhena do; ISAAC, Victoria Judith. Desembarques da Pesca de pequena Escala no município de Bragança-PA, Brasil: esforço e produção In: Boletim do Laboratório de Hidrobiologia, 25 (1): 31-48. 2012.

INGOLD, Tim. The Perception of the Environment: essays in livelihood, dwelling and skill. London: Routledge, 2000.

LE COFF. Jacques. História e Memória. Campinas: SP Editora da UNICAMP, 1990.

MEIRELES, Cecilia. Pescaria In: Ou isto ou aquilo. Rio de Janeiro: Editora Nova Fronteira, 1990.

PEIXOTO, Ana Carolina Beltrão. Pescador de ilusões: o trabalho da pesca artesanal e a sustentabilidade do desenvolvimento em comunidades pesqueiras nos municípios de Pão de Açúcar e Olho D'Agua do Casado no Baixo São Francisco alagoano. UFPE, 2011. Disponível em:

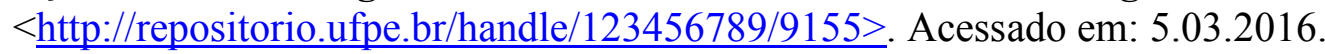

SANTOS, Milton. A natureza do espaço: técnica e tempo, razão e emoção. $4^{\circ}$ ed. São Paulo: Edusp, 2003.

SANTOS, Marcos Antônio; FILHO, Mario Corino; NEVES, Paulo Rogério; AGUIAR, Cláudia Glaucilene. Análise socioeconômica da pesca artesanal no Nordeste Paraense. XLIII Congresso da SOBER. Ribeirão Preto: 24 a 27 de Julho de 2005.

Notas:

${ }^{\mathrm{i}}$ Poema Cecilia Meireles.

ii Ingold (2000) tem uma ampla discussão entre humanos e não humanos, a inter-relação entre ambos gera consequências que se refletem em maior ou menor intensidade para todos os envolvidos. Da mesma forma que os pescadores tem uma intima relação com a água e sobre ela conseguem se constituir enquanto pescadores, a água também tem um histórico dessa relação. 